\title{
DEVELOPING AN INTERGENERATIONAL CURRICULUM MODULE BASED ON SKILL SHARING
}

\author{
Ngu Kee Shing a, Saedah Siraj b, Norlidah Alias c, \\ Husaina Banu Kenayathula ${ }^{\mathrm{d}}$, Dorothy DeWitt ${ }^{\mathrm{e}}$, Zaharah Hussin ${ }^{\mathrm{f}}$ \\ abcdef University of Malaya, Kuala Lumpur, Malaysia \\ Corresponding email: keeshing192123@siswa.um.edu.my
}

\begin{abstract}
The purpose of this paper is to obtain expert consensus on the design of the intergenerational module for the elderly and the children. This research is a quantitative method to obtain the expert opinions. A total of 21 experts in elderly education, school counselors, academic experts, experts in gerontology and advisers to senior citizens associations were selected to analyze the fuzziness of expert consensus. The questionnaire containing 6 main items was given to experts. Consensus from the experts were further analysed using Fuzzy Delphi technique. Overall, the findings of the study found that expert consensus on the types of the intergenerational module. Panel experts agreed on the design of the intergenerational module that are elders serve the youth, shared program and reciprocal mutual learning. These modules can be used as a design module that suitable in the Malaysian context because consensus of experts is more than $75 \%$ with a threshold value $(\mathrm{d}) \leq 0.2$.
\end{abstract}

Keywords: Intergenerational Program, Program Design \& Fuzzy Delphi Method.

\section{Introduction}

In Malaysia the percentage of elderly over the age of 65 had drastically increased in the recent years. Out of the total population in Malaysia, the percentage of senior citizens it had increased from 3.2 per cent (1970) to 5.0 per cent in 2010 and Malaysia is expected to reach the status of elder country in 2040 when $\mathbf{1 1 . 4}$ per cent of the total population is comprised of the elderly. With the increase of life expectancy of the population this phenomenon will continue increasing. The life expectancy for Malaysians in the year 2000 was 70 years for men and 74.7 years for women. However in 2010 it increased to 71.7 years for men and 76.6 years for women (Economic Planning Unit, 2011).

Based on this situation experienced and knowledgeable healthy senior citizens can still contribute actively to the community. Therefore this intergenerational programme aimed to improve the quality of life of senior citizens populations through various lifelong formal or informal learning programme to enable them to contribute to the Malaysian society especially through the programme. The intergenerational programme can be considered as an activity to promote cooperation, interaction and partnership between two generations. This involves the sharing of knowledge skills and experience between both parties. Therefore the intergenerational programme seeks to address the generation gap and promote positive interaction between generations (Chorn Dunham \&Casadonte, 2009; Powers, Gray,\& Garver, 2013). 


\section{The concept of intergenerational programmes}

The intergenerational field of study emerged for the first time in 1960 which established a relationship between children and the elderly in joint activities (Hanks \& Ponzetti, 2004). Since then the intergenerational programme had grown rapidly. At present the intergenerational study programme had become an interdisciplinary study and there were many programmes and resources especially in the United States (Newman, 2003). According to Alan Hatton-Yeo, Jumbo Klerg and Tosio Ohsako (2004), the intergenerational programme is a tool for the exchange and sharing of resources and continuous learning among the old and the young. While according to McCrea, Wissmann, and Thorpe-Brown (2004), the intergenerational programme is to foster interaction between children and the elderly which were carried out on an ongoing basis. Ventura-Merkel and Liddoff (1983) defined the intergenerational programme as an activity or programme to improve the cooperation, interaction and partnership between two generations. Newman (1997) see the intergenerational programme as an element specially designed to strengthen the bond between the two generations, promote the culture of sharing and provide positive support system to maintain intergenerational welfare. Hence this study is conducted to determine the design of intergenerational education modules appropriate in the context of Malaysia.

\section{Purpose of Study}

The propose of the study is to get experts approval on the program design of intergenerational education modules for elderly and students. Its objective is to identify suitable design, components and activities of intergenerational activities for students and senior citizens. In meeting the objectives outlined, this study is done for answers to following questions;

a) What is the suitable intergenerational module for the senior citizens according to experts opinion?

\subsection{Scope and Limitation}

The focus of the study is on the education module for senior citizens in the Klang Valley. A total of 21 experts had been selected as panel in this study and the selection is based on the Fuzzy Delphi provisions. (Adler \& Ziglio,1996). Selected experts were those with experience on senior citizens and students.

\section{Research Design}

This study used the Fuzz Delphi techniques to get experts consensus to design an intergenerational education module suitable for senior citizens and the younger generations in Malaysia.

\section{1 Research Samples}

Experts in this research were those who had directly involved with senior citizens and students. A total of 21 experts had been selected as panel in this study. They comprised of gerontology officers, counselor, senior citizens centre officers and officers conducting a lifelong activity at Gerontology Institute, University Putra Malaysia. The number of experts in this study is in accordance to the number stated by Jones and Twiss (1978) and Alder and Ziglo (1996). According to Jones and Twiss (1978) the number of experts for Delphi study is between 10 to 50 persons. 


\subsection{Data Collection Procedures}

The data collection process in Fuzzy Delphi method begins with the following steps.

1. Determine the number of experts involved in the study. This study selected 21 experts for consensus

2. Determine the linguistics scale (Triangular fuzzy number) This study uses linguistics 5 scales variables as in Table 1

Table 1: Fuzzy Scale

\begin{tabular}{ll}
\hline Linguistics variables & Fuzzy Scale \\
Strongly Disagree & $($ o.o.o.o,o.2) \\
Do Not Agree & $($ o.o.o.2,0.4) \\
Not Sure & $(0.2,0.4,0.6)$ \\
Agree & $(0.4,0.6 .0 .8)$ \\
Strongly agree & $(0.6,0.8,1.0)$ \\
\hline
\end{tabular}

3. All data are scheduled for the average value (m1.m2.m3) namely Minimum Value, Reasonable Value and Maximum Value

4. Determine the distance between numbers to determine the threshold value (d) using the formula: $d$ value must be less or equivalent with 0.2

5. Determine the group consensus. Percentage of group for $\mathrm{d}$ value must be above $75 \%$

6. Determine the Fuzzy aggregate evaluation by adding all Fuzzy numbers

7. Defuzzification process. This process is to determine the ranking for all variables /subvariables. The formula that can be applied:

$\operatorname{Amax}=1 / 3 *(\mathrm{al}=\mathrm{am}+\mathrm{a} 2)$

\subsection{Data Analysis and Discussion}

The following are the findings of data analysis to answer the research questions on the aspect related to the format of intergenerational module suitable in the Malaysian context.

\section{Experts consensus on the Intergenerational Education Module}

Table 2: Intergenerational Education Module

\begin{tabular}{ll}
\hline Item & \\
\hline 1. & Youth Serving elders \\
2. & Elders serving youth \\
3. & Shared Program \\
4. & Reciprocal mutual learning \\
\hline
\end{tabular}

Table 2 shows 4 classifications in the Intergenerational Education Module namely youth serving elders, elders serving youth, shared programme and reciprocal mutual learning.The threshold (d) experts consensus percentage, defuzzification and ranking item for the above items were shown in Table 3 
Table 3: Experts Consensus Percentage, Defuzzification and Ranking item

\begin{tabular}{cccc} 
Modul Classification & $\begin{array}{c}\text { Expert } \\
\text { Consensus(\%) }\end{array}$ & $\begin{array}{c}\text { Defuzzification } \\
\text { Value } \\
0.619\end{array}$ & Ranking \\
$\begin{array}{c}\text { Youth Serve the } \\
\text { Elders }\end{array}$ & 52 & 0.533 & - \\
$\begin{array}{c}\text { Elders Serve the } \\
\text { Youth }\end{array}$ & 76 & 0.724 & 3 \\
$\begin{array}{c}\text { Shared Program } \\
\text { Reciprocal mutual } \\
\text { learning }\end{array}$ & 91 & 0.676 & 1 \\
\hline
\end{tabular}

Based on table 3, panel of experts agreed that intergenerational education module be carried out based on shared and reciprocal mutual learning programme and elders serve the youths due to threshold (d) value is $91 \%, 95 \%$ and $76 \%$ which is more than $75 \%$. Experts reject the youth serving elders module because the (d) value is only $52 \%$. In terms of position, panel agreed that the intergenerational education module be carried out under the shared programme followed by reciprocal mutual learning programme.

\section{Consensus of experts on Intergenerational Education Module Design}

In this study, the focus on the Intergenerational Education Module given to experts were disclosed in Table 4.

Table 4: Intergenerational Education Module Design Focus
1. School oriented
2. Community oriented
3. Services and learning
4. Tutorial
5. Mentor
6. Sharing site
7. Senior Citizen Centre based

Based on Table 5 item 2, item 3, item 5 and item 6 was accepted due to the d value exceeded 75 $\%$. This means the experts panel agreed that the intergenerational education module design being carried based on the community ( $d$ value $=100 \%$ ), service-based learning ( $d$ value 100\%) mentor-based ( $d$ value 91\%) site-sharing ( $d$ value $95 \%$ ).

Table 5: Experts Consensus Percentage, Defuzzification and Ranking item

\begin{tabular}{cccc}
\hline $\begin{array}{c}\text { Intergenerational } \\
\text { Educational Module }\end{array}$ & $\begin{array}{c}\text { Evperts } \\
\text { Consensus(\%) }\end{array}$ & $\begin{array}{c}\text { Defuzzification } \\
\text { Value }\end{array}$ & Ranking \\
$\begin{array}{c}\text { Focus } \\
\text { School Oriented }\end{array}$ & 67 & 0.533 & - \\
Community Oriented & 100 & 0686 & 1 \\
Services and & 100 & 0.686 & 1 \\
Learning & & & \\
Tutorial & 47 & 0.533 & - \\
Mentor & 91 & 0.657 & 3
\end{tabular}




\begin{tabular}{cccc} 
Sharing Site & 95 & 0.657 & 3 \\
$\begin{array}{c}\text { Senior Citizen Centre } \\
\text { based }\end{array}$ & 52 & 0.533 & - \\
\hline
\end{tabular}

\section{Experts Consensus on students targeted for the Intergenerational Education Module}

In this study the targeted students given to experts is as stated in Table 6 Table 6:Targeted group of students for the Intergenerational Education Module
1. Kindergarten students
2. Primary School students
3. Secondary School students
4. University students

Based on Table 6 , there were 4 targeted group of students in the Intergenerational Education Module. The threshold (d) value, experts consensus percentage, defuzzification and ranking item for the above items were shown in Table 7.

Table 7: Experts Consensus Percentage, Defuzzification and Ranking item

\begin{tabular}{llll}
\hline Targeted Students & Expert & Defuzzification & Ranking \\
& Consensus\%) & Value & \\
Kindergarden & 38 & 0.571 & 4 \\
Primary School & 95 & 0.600 & 3 \\
Secondary School & 95 & 0.657 & 2 \\
University & 95 & 0.705 & 1 \\
\hline
\end{tabular}

Based on Table 7, only item 2, item 3 and item 4 that have the d value exceeding $75 \%$. This means that the experts panel agreed that the intergenerational education module is done on primary, secondary and university students. The experts panel do not agree on the module done on kindergarten students $(\mathrm{d}=38 \%)$. The panel approval was based on the defuzzification value.

\section{Experts Consensus on the location for Intergenerational Education Module}

In this study, the location for the education module given to experts were stated in Table 8 .

Table 8: Location for the Intergenerational Education Module

1. School

2. Community centre

3. Senior Citizen centre

4. Hospital

Table 8 showing the types of location for the module. The threshold (d), experts consensus percentage, defuzzification and ranking item for the above items were shown in table 9.

Table 9: Experts Consensus Percentage, Defuzzification and Ranking item 


\begin{tabular}{llll}
\hline Location & Expert & Defuzzification & Ranking \\
& Cinsensus(\%) & Value & \\
School & 81 & 0.619 & 3 \\
Community centre & 90 & 0.695 & 1 \\
Senior Citizen centre & 90 & 0.648 & 2 \\
Hospital & 95 & 0.505 & 4 \\
\hline
\end{tabular}

Based on Table 9 all items have the d value exceeding $75 \%$.meaning that the experts panel agreed that the intergenerational education module to be done at all location namely community centre, followed by senior citizen centre, schools and hospitals.

\section{Experts consensus on the appropriate timing for conducting the Intergenerational Education Module}

In this study, timing for the module given to experts were as stated in Table 10.

Table 10: Timing for conducting the Intergenerational Education Module
1. Weeks
2. Days
3. Months
4. School holidays

Table 10 shows the appropriate timing for the module. Threshold (d), experts consensus percentage, defuzzification and raking items on the aspect of timing were shown in Table 11.

Table 11: Experts Consensus Percentage, Defuzzification and Ranking item

\begin{tabular}{llll}
\hline Timing & Expert & Defuzzification & Ranking \\
& consensus(\%) & Value & \\
Weeks & 52 & 0.600 & - \\
Days & 71 & 0.352 & - \\
Months & 86 & 0.648 & 2 \\
School holidays & 90 & 0.714 & 1 \\
\hline
\end{tabular}

Based on Table 11 only item 3 and 4 has the d value exceeding $75 \%$. This means that the experts panel agreed that the intergenerational education module being conducted during school holidays and on monthly basis. The panel disagreed on conducting the module on weekly ( $d$ value $=52 \%)$ and daily basis $(d=71 \%)$. The panel agreed that the education module being conducted during school holidays, and monthly based on the defuzzification values.

\section{Experts consensus on the joint institutions for Intergenerational Education Module}

In this study the joint institutions given to experts for the module were as stated in Table 12.

Table 12: Joint Institutions for conducting the Intergenerational Education Module 
1. Schools

2. Parents Teachers Association

3. Senior Citizen Centres

4. Religious organisations

5. Government Agencies

6. Community Centres

7. Non-Governmental Association (NGO)

8. Private sectors

Table 13: Experts Consensus Percentage, Defuzzification and Ranking item

\begin{tabular}{|c|c|c|c|}
\hline Joint Institution & $\begin{array}{l}\text { Expert } \\
\text { Consensus(\%) }\end{array}$ & $\begin{array}{l}\text { Defuzzification } \\
\text { Value }\end{array}$ & Ranking \\
\hline School & 67 & 0.590 & 8 \\
\hline $\begin{array}{l}\text { Parents Teacher } \\
\text { association }\end{array}$ & 67 & 0.610 & 7 \\
\hline $\begin{array}{ll}\text { Senior } & \text { Citizen } \\
\text { Centres } & \end{array}$ & 95 & 0.657 & 4 \\
\hline $\begin{array}{l}\text { Religious } \\
\text { organisations }\end{array}$ & 48 & 0.629 & 6 \\
\hline Governmet Agencies & 95 & 0.638 & 5 \\
\hline Community Centres & 100 & 0.695 & 2 \\
\hline $\begin{array}{l}\text { Non-Governmental } \\
\text { Associations }\end{array}$ & 100 & 0.714 & 1 \\
\hline Private Sectors & 95 & 0.695 & 2 \\
\hline
\end{tabular}

Based on Table 13, items 3,5,6,7 and 8 have the d value exceeding $75 \%$, meaning that that the experts agreed that the educational module should have joint institutions such as senior citizen centres, government agencies, community centres, voluntary organisations and private sector for the success of the intergenerational programmes.

\section{Discussions and Implications of Study}

Overall findings of this study: The development of design for intergenerational education module indicated that the experts agreed on its suitable designs. The experts panel agreed on three designs namely elders serve the youth, shared programme and reciprocal mutual learning to be implemented in the context of Malaysia. This is in line with guidelines issued by researchers (generation United,2013; Jarot,2011) on guidelines and strategy to implement intergenerational design activities. Findings of this study supports the research by Bishop and Moxley (2012) which issued ten statements to develop intergenerational programme. This research findings is also in accordance with six standards issued by Rosebrook dan Larkin (2003) on guidelines and standards to practice intergenerational programme.

Secondly the Fuzzy Delphi technique findings have proposed community-based, service-based learning, mentor-based and sharing site as intergenerational module design that could be implemented for senior citizens and secondary school students. This supports research findings Generation United ,2013; Knap \& Stubblefield, 2000; Thang, Kaplan \& Henkin,2003; Weinreich,2003) which indicated that the community, service and learning 
based intergenerational module design are able to encourage good interaction between senior citizens and students.

The intergenerational education module design established through expert consensus had given input to voluntary bodies and non-governmental organisations to carry out intergenerational activities and programmes that are suitable with the needs and skills of senior citizens as well as kindergarten, school and university students. This Intergenerational Education Module encourage government agencies and voluntary organisations including the NGO's to undertake intergenerational activities that is suitable on their level of needs and interests based on the module guidelines.

\section{Conclusion}

Findings through Fauzzy Delphi technique using a 21 expert panel had suggested Intergenerational Education Module elements suitable for senior citizens and students. Based on social constructivism theory, elements in the module which was agreed by experts can be an example on how senior citizens can share their skills with students as describe by Vygotsky (1978) in the proximal development zone theory .

Based on Allport (1955) Contact Theory, senior citizens and students interaction can be upgraded through frequent interaction in carrying out joint activities . Hence activities planned must reflect the objectives and needs of senior citizens and students (Hattan-Yeo \& Ohsako,2000; Springate, Atkinson \&Martin 2008). Intergenerational activities that favours to students or senior citizens must be avoided (Salari,2002). As explained in 2 pillar contact theory, senior citizens and students should be given the same status and role and intergenerational activities planned must take into consideration on the experience and needs of both parties.

Briefly, this study reflected the uniformity of the findings with the past research especially on the design of intergenerational education module. What matters most is that this research is an effort towards developing a more structured intergenerational module for senior citizens and students in the country. 


\section{References}

i. $\quad$ Adler, M. \& Ziglio, E., 1996. Gazing into the oracle. Bristol, PA: Jessica Kingsley Publishers.

ii. Bishop, J. \& Moxley, D., 2012. Promising Practices Useful in the Design of an Intergenerational Program: Ten Assertions Guiding Program Development. Social Work in Mental Health, 10(3), pp. 183-204.

iii. Dunham, C. C. \& Casadonte, D., 2009. Children's Attitudes and Classroom Interaction in an Intergenerational Education Program. Educational Gerontology, 35(5), pp. 453-464.

iv. Generations United, 2013. Intergenerational Programs Engaging Youth in service to older adults. [Online] Available at: http://www.gu.org/RESOURCES/Publications.aspx

v. Hanks, R. \& Ponzetti., 2004. Family Studies and Intergenerational Studies. Journal of Intergenerational Relationships, 2(3), pp. 5-22.

vi. Hatton-Yeo, A., Klerq, J. \& Ohsako, S., 200o. Public Policy and recommendations : an international perspective. In International Programmes:Public Policy and Research Implications.An International Perspective. s.l.:The UNESCO institute for Education The Beth Johnson Foundation..

vii. Jarrott, S., 2011. Where have we been and where are we going? Content analysis of evaluation research of intergenerational programs. Journal of Intergenerational Relationships, 9(1), pp. 3752.

viii. Knapp, J. \& Stubblefield, P., 2000. Changing students' perceptions of aging: the impact of an intergenerational service learning course. Educational Gerontology, Volume 26, pp. 611-621.

ix. $\quad$ Malaysian Quality Of Life, 2011. Malaysian Quality Of Life, s.l.: Malaysian Quality Of Life.

x. McCrea, J., Wissmann, M. \& Thorpe-Brown, G., 2004. Connecting thee Generations: A Practical Guide for Developing Intergenerational Programs. Pittsburgh, PA: Generations Together.

xi. Newman, S., 1997. History and Evolution of Intergenerational Programs. Intergenerational Programs, Past, Prsent and Future. Washington DC: Taylor and Francis.

xii. Newman, S., 2003. An introductory message from the editor. Journal of Intergenerational Relationships, 1(1), pp. 1-4.

xiii. $\quad$ Powers, M., Gray, M. \& Garver, K., 2013. Attitudes Toward Older Adults: Results from a FitnessBased Intergenerational Learning Experience. Journal of Intergenerational Relationships, 11(1), pp. 50-61.

xiv. Rosebrook, V. \& Larkin, E., 2003. Introducing standards and guidelines. Journal of Intergenerational Relationships, 1(1), pp. 133-141.

xv. S.Salari, 2002. Intergenerational partnerships in adult day centers: Importance of ageappropriate environments and behavior. The Gerontologist, Volume 42, pp. 31-333.

xvi. Springate, I., Atkinson, M. \& Martin, K., 2008. Intergeenrational Practice : A Review of the Literature, Slough: National Foundation for Research Report.

xvii. Thang, L., Kaplan, M. \& Henkin, N., 2003. Intergenerational programming in Asia: Converging diversities toward a common goal. Journal of Intergenerational Relationships, 1(1), pp. 49-69.

xviii. Unit Economic Planning, 2011. Malaysian Quality Of Life. Kuala Lumpur: Percetakan Nasinal Malaysia Berhad. 
xix. Ventura-Merkel, Dan, C. \& Liddoff, L., 1983. Program Innovation in Aging: Community Planning for Intergenerational Programming. Washington DC: National Council on Aging.

xx. Weinreich, D., 2003. Service-Learning At the Edge of Chaos. Educational Gerontology, 29(3), pp. 181-195. 